\title{
Effect of board density and layer structure on the mechanical properties of bamboo oriented strandboard
}

Note

Ihak Sumardi: Ph.D candidate, Faculty of Agriculture, Shizuoka University

Kazuhiro Ono: Senior Researcher, Shizuoka Prefecture Forestry and Forest Products Research Institute

Shigehiko Suzuki: Professor, Faculty of Agriculture, Shizuoka University (Corresponding $\bowtie$ )

Address of authors:

I. Sumardi $\cdot$ S. Suzuki $(\bowtie)$

Wood Science, Faculty of Agriculture, Shizuoka University, 836 Ohya, Shizuoka 422-8529, Japan Tel. +81-54-238-4854; Fax +81-54-237-3028

e-mail: afssuzu@ipc.shizuoka.ac.jp

K. Ono

Shizuoka Prefecture Forestry and Forest Products Research Institute, Shizuoka 430-0016, Japan 


\begin{abstract}
This study examined the effect of density and layer structure on the mechanical properties and dimensional stability of strandboard manufactured from moso bamboo (Phyllostachys pubescens). The strandboard was fabricated in a laboratory at five densities and three different structures including a randomly oriented homogenous board, a unidirectionally oriented homogenous board, and a three-layered board with a cross-oriented core layer (BOSB). Bamboo strand alignment distribution could be predicted using the von Mises distribution function. Bending properties increased with increasing density and were affected by layer structure. The modulus of rupture (MOR) of the three-layered board in the parallel direction increased remarkably compared with the random board MOR; in the perpendicular direction, it exhibited less strength reduction. Elastic properties of the three-layered board could be predicted using elastic constants of the unidirectional board. Internal bond strength (IB) was greatly affected by density, but the layer structure effect did not appear in IB. Linear expansion per unit moisture change ranged from 0.017 to 0.022 for random and three-layered boards; these values are comparable with or lower than values for commercial board.
\end{abstract}

\title{
Key words
}

Bamboo $\cdot$ Density $\cdot$ Dimensional stability $\cdot$ Mechanical properties $\cdot$ Oriented strandboard

\section{Introduction}

Bamboo has been widely used in Asian countries as a traditional material for housing construction, furniture manufacture, and articles for daily life such as fans, chopsticks, and baskets owning to its high strength and surface hardness, superior flexibility, and stable properties. ${ }^{1}$ Bamboo is also a fast-growing and nonwoody lignocellulosic material that has been shown to exhibit equal or better physical and mechanical properties in comparison with some commercial wood species. ${ }^{1}$ It has gained increasing interest in recent years as an alternative material to wood or wood-based materials, and can be used as a raw material for wood-based panel products.

Several articles have reported using bamboo in various composite panels; Chen ${ }^{2}$ studied the use of bamboo plywood as a structural material, and Nugroho and $\mathrm{Ando}^{3}$ fabricated a new product called zephyr board. Studies have evaluated the dimensional stability of bamboo particleboard ${ }^{4,5}$ and the manufacturing technology for bamboo fiberboard and medium-density fiberboard (MDF). ${ }^{6-8}$ Researchers have also manufactured other panel composites such as bamboo-based waferboard ${ }^{9}$ and oriented strandboard (OSB $)^{10}$ to examine their properties. Although many studies have examined bamboo-based panel products, few have been conducted to evaluate the properties of OSB made from bamboo. Lee at al. ${ }^{10}$ reported that bamboo strandboard showed values of internal bond strength (IB), modulus of elasticity (MOE), and modulus of rupture (MOR) in both the parallel and perpendicular directions that were higher than the standards proposed for commercial OSB and waferboards. 
In contrast, many studies have focused on improving the physical and mechanical properties of wood OSB and on utilizing new species as raw materials for commercial production. Wood OSB studies have mainly focused on parameters such as board density and mechanical properties, ${ }^{11,12}$ layer structure, ${ }^{12-14}$ strand length, ${ }^{15,16}$ and linear expansion. ${ }^{17}$ Understanding these basic properties is important when discussing the potential use of bamboo as a raw material for OSB manufacturing.

The objective of this study was to determine the effects of density and layer structure on the mechanical properties and dimensional stability of bamboo strandboard; to this end, bamboo strandboard was fabricated in a laboratory at various densities and layer structures.

\section{Materials and methods}

Strand preparation

Strands were prepared from moso bamboo (Phyllostachys pubescens) collected from a bamboo forest near the city of Tenryu in the western region of Shizuoka Prefecture, Japan. The density of bamboo used as raw material was approximately $0.60 \mathrm{~g} / \mathrm{cm}^{3}$. Each bamboo pole was cut from its base to a height of approximately $8 \mathrm{~m}$, and was stranded in a local strandboard mill using a disk-type flaker. Target strand dimensions were $50 \mathrm{~mm}$ long, $0.5 \mathrm{~mm}$ thick, and 5-20 $\mathrm{mm}$ wide. The actual dimensions, determined by using 100 pieces of strand, were $47 \mathrm{~mm}$ long, $0.45 \mathrm{~mm}$ thick, and $7.3 \mathrm{~mm}$ wide. Strands were screened on a 10-mesh sieve before being dried in a $60^{\circ} \mathrm{C}$ rotary oven to a moisture content of less than $3 \%$.

\section{Board fabrication}

Strandboards were manufactured using a commercial liquid phenolic resin with $51 \%$ solid content to the nominal dimensions of $400 \times 400 \times 12 \mathrm{~mm}$. No waxes or other additives were applied. Hand-formed mats were pressed for $10 \mathrm{~min}$ at a temperature of $180{ }^{\circ} \mathrm{C}$; the maximum pressure applied was $8 \mathrm{MPa}$. No surface sanding was performed. A $6 \%$ resin content was applied to strands using a pressurized spray gun in a rotary type blender. Three types of board were fabricated, each with a different layer structure: a three-layered oriented strandboard (BOSB) with a cross-oriented core layer (layer structure was based on final oven-dried weight, and the face/core/face ratio was 25:50:25), a unidirectionally oriented homogenous board (UNID), and a randomly oriented homogenous board (RAND). A set of thin plates with 20-mm spacing was used as an orienter during BOSB and UNID board mat forming. Strand free fall distances (FFD) were maintained at $20 \pm$ $5 \mathrm{~mm}$.

Specimens were manufactured to have five density levels: $0.49,0.57,0.65,0.73$, and $0.81 \mathrm{~g} / \mathrm{cm}^{3}$. Two panels were produced for each density level and each type of layer structure.

\section{Alignment angle measurement}

To determine the strand alignment angle distribution in BOSB and UNID boards, photos of strands 
were recorded as digital image data for measuring orientation angles. Deviation between orientation and strand length direction angles were determined using 1000 strands oriented at a 20-mm FFD and with 20-mm plate spacing.

Evaluation of mechanical properties

Prior to testing, all boards were fully conditioned at a relative humidity (RH) of $65 \%$ and a temperature of $25^{\circ} \mathrm{C}$. Bending and internal bond strength tests were conducted in accordance with the Japanese Industrial Standard (JIS) for particleboard. ${ }^{18}$ During mechanical tests, five trials were performed for each type of sample to measure MOE and MOR in bending, and seven trials were performed for each type of sample to measure IB strength.

Density profiles in thickness direction of the specimens were measured using a commercial density profiler based on a gamma radiation system. Two specimens with dimension of $50 \times 50 \mathrm{~mm}$ were used, and the measurement was made at $0.1-\mathrm{mm}$ intervals.

To determine dimensional stability, the thickness swelling (TS) in seven specimens was measured at each step of a wet-dry cyclic aging treatment. During the first cycle of this process, boards were soaked in water at $20^{\circ} \mathrm{C}$ for $24 \mathrm{~h}$ (W1) and then dried at $50^{\circ} \mathrm{C}$ for $22 \mathrm{~h}$ (D1); during the second cycle, boards were soaked in water at $70^{\circ} \mathrm{C}$ for $2 \mathrm{~h}$ (W2) and then dried at $50^{\circ} \mathrm{C}$ for $22 \mathrm{~h}$ (D2); during the third cycle, they were soaked in water at $100^{\circ} \mathrm{C}$ for $2 \mathrm{~h}$ (W3) and dried at $50^{\circ} \mathrm{C}$ for $22 \mathrm{~h}$ (D3). After these treatments, specimens measuring $50 \times$ $50 \mathrm{~mm}$ were conditioned at $25^{\circ} \mathrm{C}$ and $65 \pm 5 \% \mathrm{RH}$ until they reached equilibrium.

Linear expansion (LE) was evaluated using two specimens with dimensions of $300 \times 50 \mathrm{~mm}$, based on initial measurements taken after boards were dried at $60^{\circ} \mathrm{C}$ for $22 \mathrm{~h}$. Changes in length were regularly measured during treatment in humid conditions of $40^{\circ} \mathrm{C}$ and $90 \% \mathrm{RH}$ for $150 \mathrm{~h}$, followed by dry conditions of $60^{\circ} \mathrm{C}$ for $150 \mathrm{~h}$, using a dial gauge comparator. ${ }^{19}$

\section{Results and discussion}

Orientation angle

When examining the effects of orientation on the mechanical properties of OSB, alignment angle distribution is used as basic information. This distribution could depend on orienting conditions such as FFD, plate spacing, and shape of the strand. Figure 1 shows the distribution of angle deviation among bamboo strands oriented under identical conditions for BOSB and UNID board fabrication. The bar chart displays measurement results. Curve fitting used a modified von Mises distribution function. ${ }^{20,21}$

$$
f(\mathrm{x}, \mathrm{k})=\frac{1}{\pi \mathrm{I}_{0}(\mathrm{k})} \exp (\mathrm{k} \cos 2 \mathrm{x})
$$

where $x$ is an angle defined between $-\pi / 2$ and $\pi / 2, k$ is the concentration parameter, and $I_{0}$ is a modified Bessel function of the first kind and order zero. The value of $k$ was obtained by the least squares method. 
Results revealed an estimated $\mathrm{k}$ value of 2.0. Geimer's percent alignment ${ }^{22}$ was used as another index to analyze distribution, and produced a value of $57 \%$. In a previous study, Nishimura et al. ${ }^{23}$ measured the strand orientation angles of 26 commercial OSBs, and found that Geimer's percent alignment ranged from $11 \%$ to $44 \%$, which corresponds to $k$ values of 0.28 to 1.4 . These results indicate that the BOSB and UNID boards in this study had superior orientation to commercial OSBs.

Effect of layer structure on mechanical properties

Mechanical properties were affected by both layer structure and density, as shown in Fig. 2. The MOR of each board type increased almost linearly with increasing board density; many studies of the relationships between density-mechanical properties have reported similar results. The inclination of MOR seemed to be slightly greater at board densities higher than $0.57 \mathrm{~g} / \mathrm{cm}^{3}$ compared with densities below that, at which point the board compaction ratio was around unity.

Strength ratio could be an indicator of board strand alignment and layer structure. Comparison of MORs at a density of $0.65 \mathrm{~g} / \mathrm{cm}^{3}$ revealed that in UNID board, the MOR in the oriented direction was 9.2 times that in the perpendicular direction, and was 2.4 times that in RAND board. These values were higher than those of sugi OSB. ${ }^{16}$ In BOSB board, the MOR in the perpendicular direction was 2.4 times that in the cross-oriented direction, and was 1.8 times that in RAND board. Comparison of MORs in BOSB and RAND board revealed that a three-layer structure provided higher MOR in the parallel direction with less strength reduction in the perpendicular direction, as shown in Fig. 2.

A similar trend in density was observed in MOE, as shown in Fig. 3. The MOE ratios for UNID board in the parallel direction at a board density of $0.65 \mathrm{~g} / \mathrm{cm}^{3}$ were 7.6 and 2.5 times, respectively, to those for the perpendicular direction of UNID board and RAND board. The MOE ratios for BOSB board were 3.7 and 2.0 times, respectively, to those for the cross-oriented direction of BOSB board and RAND board. These values approximate measurements of Douglas fir strands. ${ }^{11}$

In contrast to the difficulty in predicting MOR, ${ }^{24}$ the MOE of cross-oriented boards can be calculated on the basis of the simple combination theory of two elastic bodies. ${ }^{25,26}$ The dotted lines in Fig. 3 represent the predicted MOE in BOSB board, which was calculated using two MOEs from the parallel and perpendicular directions of UNID board as elastic constants for each layer of BOSB board. The calculation used the weight ratio of each layer (25:50:25) as the thickness ratio of each fabricated board. Although some deviations were observed between the theoretical and actual values (this was expected because the modeling was so simple), the results showed that a certain extent of accuracy in prediction could be attained. Results also suggest that elastic data from unidirectional board can be used to predict the elastic properties of three-layer bamboo board.

Internal bond

In general, internal bond failure occurs in the center line of board thickness because of the core's low density. The bamboo strandboards used in this study also exhibited failure in the middle layer of all board types. 
The density gradient in the thickness direction of random boards was prominent in higher density board, such as boards with densities of $0.81 \mathrm{~g} / \mathrm{cm}^{3}$ (Fig. 4); this result is similar to those observed in typical mat-formed panel products. However, the density gradient became unclear with decreasing density; Fig. 4 presents results for a random board with a density of $0.57 \mathrm{~g} / \mathrm{cm}^{3}$. One reason for this may have been the low compaction ratio at this density.

Internal bond strength of boards also exhibited a similar trend in bending properties as a function of density, as shown in Fig. 5. IB was greatly affected by density but was not affected by layer structure. This result was similar to those observed in bamboo $\mathrm{OSB}^{10}$ and wood OSB. ${ }^{12,15}$ It seems likely that alignment between parallel-oriented strands might provide better contact and bond quality than in randomly formed strands. However, this study could not verify these results because of the large variation in IB values.

\section{Dimensional stability}

Board dimensional stability was evaluated using thickness swelling (TS) and linear expansion (LE). Figure 6 shows an example of TS for a board with a density of $0.65 \mathrm{~g} / \mathrm{cm}^{3}$ during the cyclic wet-dry aging treatment. Results indicated that TS increased with an increased treatment cycle. Under wet conditions, TS values ranged from $12 \%$ to $17 \%, 18 \%$ to $24 \%$, and $22 \%$ to $27 \%$, respectively, for $\mathrm{W} 1$ (water immersion), W2 (hot water immersion), and W3 (boiling water immersion). Some differences in TS appeared between board types; RAND board exhibited greater TS than UNID or BOSB board in which there were significant differences at second and third cycles. This indicates that strands of the random board had been more damaged than those of the aligned boards, which were more uniformly compressed during the mat consolidation process.

This study also measured LE, which represents another structural aspect of strandboard dimensional stability. Figure 7 presents the LE behavior in boards with a density of $0.65 \mathrm{~g} / \mathrm{cm}^{3}$ after they had been subjected to a humidity test at $40^{\circ} \mathrm{C}$ and $90 \% \mathrm{RH}$ for $150 \mathrm{~h}$, followed by a drying test at $60^{\circ} \mathrm{C}$ for $150 \mathrm{~h}$. During the first $50 \mathrm{~h}$, LE increased rapidly; it leveled off at $150 \mathrm{~h}$, producing values of $1.2 \%$ for UNID-Pp (Pp denotes perpendicular orientation), $0.3 \%$ for BOSB-Pp and RAND, $0.2 \%$ for BOSB-Pr (Pr denotes parallel orientation), and $0.1 \%$ for UNID-Pp. In the drying stage, values became negative; Table 1 summarizes the results. A board's total LE (dLE) was defined as the difference between LE at $150 \mathrm{~h}$ under humid conditions and LE at $300 \mathrm{~h}$ under dry conditions. During this experiment, RAND dLE was $0.33 \%$ and the corresponding total moisture change (dMC) was $16.8 \%$; thus, the LE per unit moisture change (LE/MC) became 0.020 . This RAND board LE/MC fell between values for BOSB-Pr and BOSB-Pp. These values for random and three-layer boards are comparable with or lower than the LE/MC values for commercial and laboratory-made strandboard/OSB. ${ }^{2,27}$

Theoretically, if BOSB-Pr and BOSB-Pp had identical quantities of strands in perpendicular and parallel layers, their LE/MCs values would be the same. However, many factors other than the quantity of supply affect actual LE values. In this study, BOSB board had a LE/MC ratio of 0.80 for perpendicular to 
parallel directions. UNID board exhibited considerably different LE properties in each direction, as was expected. LE/MC for UNID-Pr was 0.009 and was 0.077 for UNID-Pp. These values can be compared with the LE per unit moisture change in solid bamboo, which a previous study ${ }^{1}$ reported as 0.001 in the longitudinal direction and 1 in the radial direction. UNID board exhibited more linear expansion in the parallel direction than solid bamboo, while UNID-Pp exhibited less. These differences may be useful in discussing how the UNID boards compare with the ideal board in which the strand are completely oriented.

\section{Conclusions}

Based on the results of this study, the effects of density and layer structure on bamboo oriented strandboard properties can be summarized as follows. The von Mises distribution function can be used to predict bamboo strand distribution. Bending properties increased with increased board density, and were also affected by layer structures. In BOSB board, the MOR in the parallel direction increased remarkably compared with the MOR in RAND board, with less strength reduction in the perpendicular direction. Elastic data from UNID board can be used to predict the elastic properties of BOSB board. IB strengths of both oriented and random boards were greatly affected by board density. TS in RAND board was slightly greater than in oriented boards, while layer structure did not appear to affect IB strength. RAND and BOSB LE/MC values ranged from 0.017 to 0.022 . These values are comparable with or lower than values for commercial boards.

Acknowledgments We thank Professor Sobue and Mr. Ikeda, Shizuoka University, for their valuable suggestions throughout the course of this study.

\section{References}

1. Lee AWC, Bai X, Peralta PN (1994) Selected physical and mechanical properties of giant timber bamboo (Phylostachys bambusoides) grown in South California. Forest Prod J 44:40-46

2. Chen GH (1985) Bamboo plywood: a new product of structural material with high strength properties. Proceedings of the 2nd International Bamboo Workshop, Hangzhou, China, pp 337-338

3. Nugroho N, Ando N (2000) Development of structural composite product made from bamboo I: fundamental properties of bamboo zephyr board. J Wood Sci 46:68-74

4. Zang M, Kawai K, Yusuf S, Imamura Y, Sasaki H (1997) Manufacture of wood composite using lignocellulosic materials and their properties III. Properties of bamboo particleboards and dimensional stability improvement using a steam-injection press. Mokuzai Gakkaishi 43:318-326

5. Sakuno T, Han KS (2003) Manufacture and properties of boards made from fresh mosochiku bamboo. Proceedings of the International Conference on Forest Products, Daejeon, Korea, pp 325-330

6. Xu Y, Zhang Y, Wang W (2001) Study on manufacturing technology of MDF from bamboo. Proceedings of the Utilization of Agricultural and Forestry Residues, Nanjing, China, pp 117-123 
7. Matsumoto K, Yamauchi H, Yamada M, Taki K, Yoshida H(2001) Manufacture and properties of fiberboard made from moso bamboo. Mokuzai Gakkaishi 47:111-119

8. Kawai S, Ohmori Y, Han GP, Adach K, Kiyooka T (2001) A trial of manufacturing high-strength bamboo fiber composite. In: Proceedings of the Utilization of Agricultural and Forestry Residues, Nanjing, China, pp 124-129

9. Zang HJ (2001) New structural panel composite: bamboo-based waferboards. Proceedings of the Utilization of Agricultural and Forestry Residues, Nanjing, China, pp 204-209

10. Lee AWC, Bai X, Paralta PN (1996) Physical and mechanical properties of strandboard made from moso bamboo. Forest Prod J 46:84-88

11. Canadido LS, Saito F, Suzuki S (1990) Influence of strand thickness and board density on the orthotropic properties of oriented strandboard. Mokuzai Gakkaishi 36:632-636

12. Kajita H (1987) Oriented particle board with sugi thinning (Criyptomeria japonica) I. Effect of degree of particle alignment and board density on physical and mechanical properties. Mokuzai Gakkaishi 33:865-871

13. Xu W, Winistorfer PM (1995) Layer thickness swell and layer internal bond of medium density fiberboard and oriented strandboard. Forest Prod J 45:67-71

14. Zhang M, Wong ED, Kawai S, Kwon JH (1998) Manufacture and properties of high performance oriented strand board composite using thin strands. J Wood Sci 44:191-197

15. Canadido LS, Saito F, Suzuki S (1988) Effect of particle shape on the orthotropic properties of oriented strand board. Mokuzai Gakkaishi 34:21-27

16. Suzuki S, Takeda K (2000) Production and properties of Japanese oriented strand board I: effect of strand length and orientation on strength properties of sugi oriented strand board. J Wood Sci 46:289-295

17. Wu Q (1996) Linear expansion and its relationship to moisture content change for commercial oriented strandboard. Forest Prod J 46:79-83

18. Japanese Industrial Standard (1994) Particleboards. JIS A 5908-1994

19. American Society for Testing and Materials (1988) Standard test methods for evaluating the properties of wood-based fiber and particle panel materials. ASTM D 1037-177, ASTM, West Conshohocken, PA

20. Abromivit M, Stegun IA (1965) Handbook of mathematical function. Downer, New York, p 1046

21. Mardia KV (1972) Statistic of directional data. Academic, New York, p 357

22. Shaler SM (1991) Comparison two measures of flake alignment. Wood Sci Technol 26:53-61

23. Nishimura T, Ansell MP, Ando N (2001) The relationship between the arrangement of wood strand at the surface of OSB and the modulus of rupture determined by image analysis. Wood Sci and Technol $35: 555-562$

24. Lee AWC, Bai X, Bang AP (1997) Flexural properties of bamboo-reinforced southern fine OSB beams. Forest Prod J 47:74-78

25. Jones RH (1975) Mechanics of composite materials. Heminespherfe, New York 
26. Lee AWC, Bai X, Bang AP (1997) Flexural properties of bamboo-reinforced southern fine OSB beams. Forest Prod J 47:74-78

27. Avramidis S, Smith LA (1989) The effect of resin content and face-to-core ration on same properties of oriented strandboard. Holzforschung 42:131-133

Table 1. Linear expansion (LE) per unit of moisture content (MC) change (LE/MC) based on differences in LE and MC between humid and dry conditions

\begin{tabular}{ccccc}
\hline \hline $\begin{array}{c}\text { Density } \\
\left(\mathrm{g} / \mathrm{cm}^{3}\right)\end{array}$ & Board type & $\begin{array}{c}\mathrm{dMC} \\
(\%)\end{array}$ & $\begin{array}{c}\mathrm{dLE} \\
(\%)\end{array}$ & $\begin{array}{c}\text { LE/MC } \\
(\% / \%)\end{array}$ \\
\hline 0.65 & Random & 16.8 & 0.33 & 0.020 \\
0.65 & UNID-Pr & 15.9 & 0.14 & 0.009 \\
0.65 & UNID-Pp & 16.3 & 1.25 & 0.077 \\
0.65 & BOSB-Pr & 16.7 & 0.29 & 0.017 \\
0.65 & BOSB-Pp & 17.0 & 0.37 & 0.022 \\
\hline \hline
\end{tabular}

dMC, total MC change; dLE, total LE change; UNID, unidirectionally oriented homogeneous board; BOSB, three-layer board with a cross-oriented core layer; Pr, parallel direction; Pp, perpendicular direction

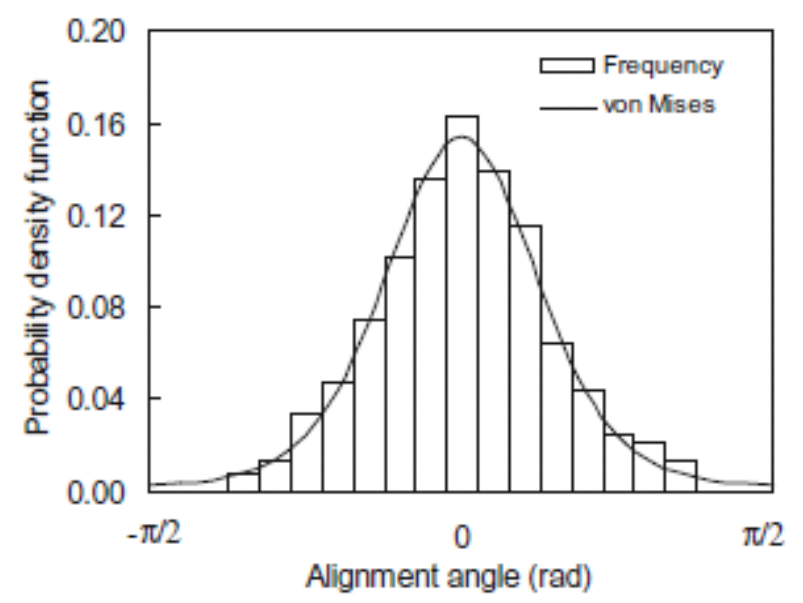

Fig. 1. Alignment angle distribution of bamboo strands at a $20-\mathrm{mm}$ at free-fall distance and plate spacing. Curve fitting: von Mises distribution function 


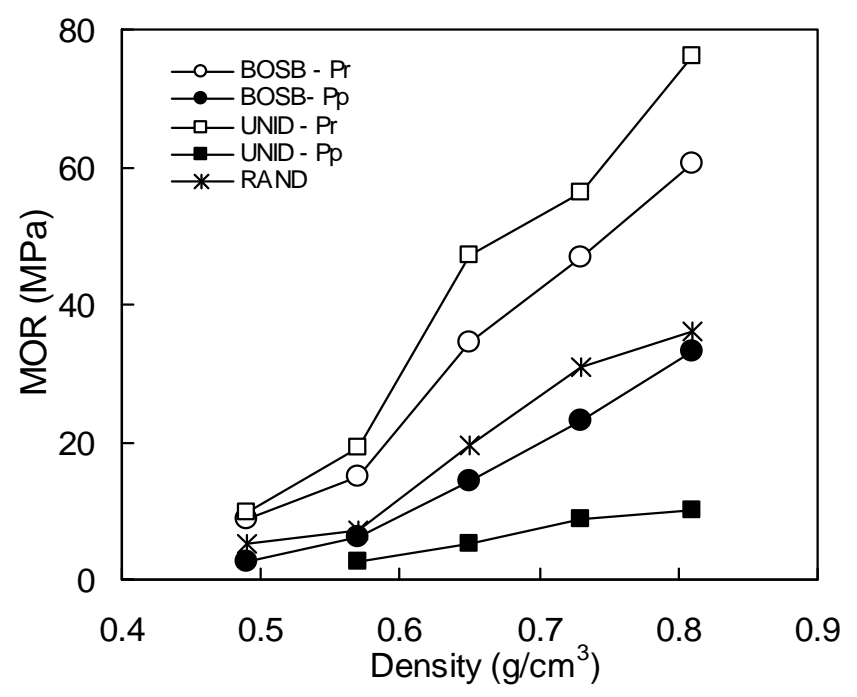

Fig. 2. Effect of board density and layer structure on modulus of rapture (MOR). RAND, randomly oriented homogenous board; UNID, unidirectionally oriented homogenous board; BOSB, three-layer board with a cross-oriented core layer; $\mathrm{Pr}$, parallel direction; $\mathrm{Pp}$, perpendicular direction

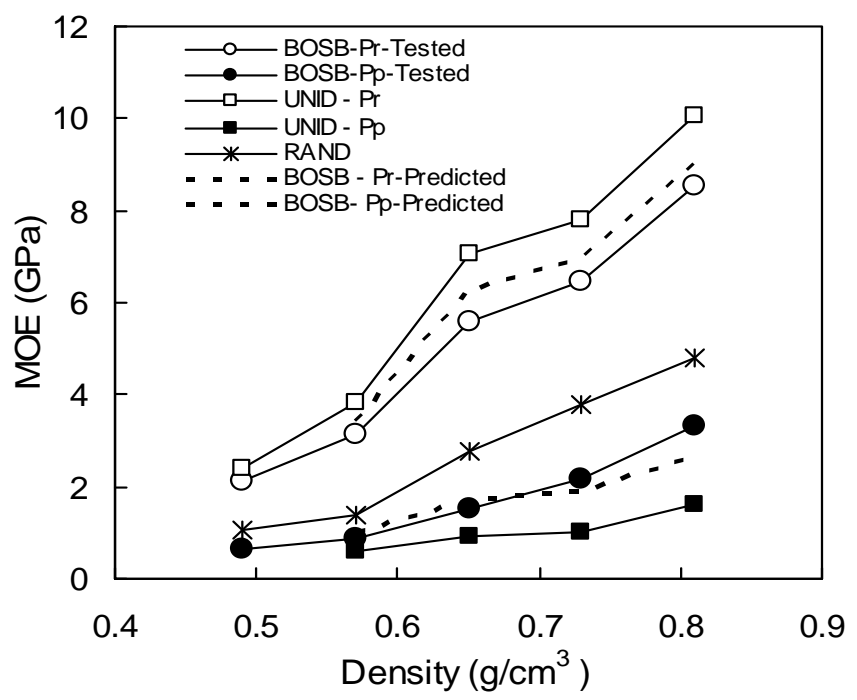

Fig. 3. Effect of board density and layer structure on modulus of elasticity (MOE). Dotted lines represent estimated MOE of BOSB board using MOEs of UNID board 


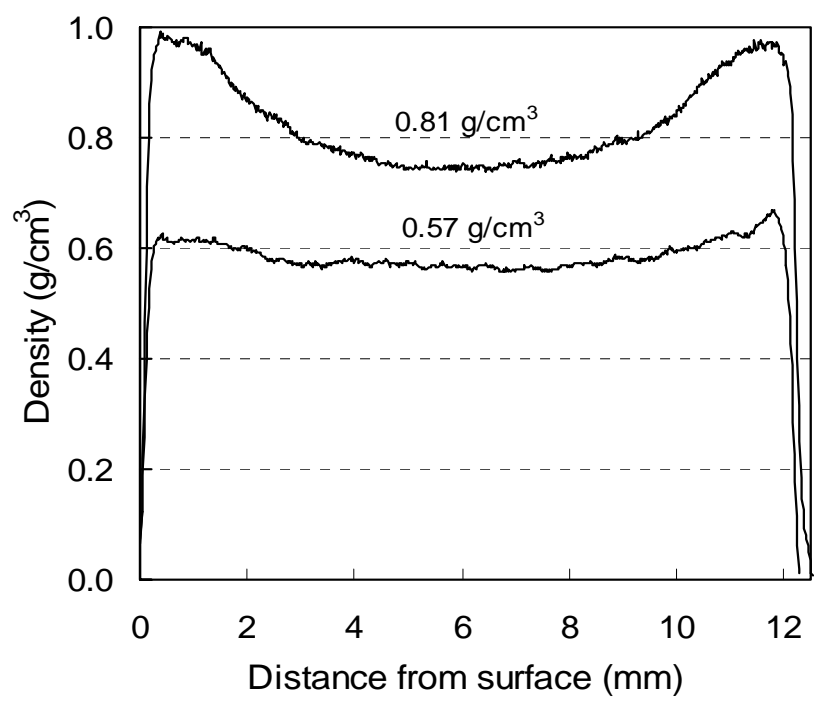

Fig. 4. Vertical density profiles of bamboo strandboard with different densities for RAND-board

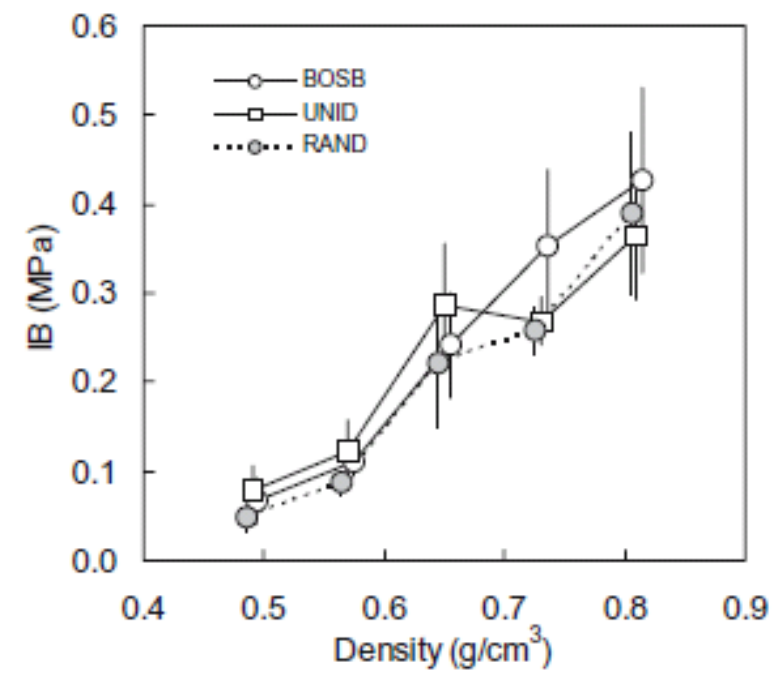

Fig. 5. Effect of board density and layer structure on internal bond strength (IB). Error bars represent standard deviation 


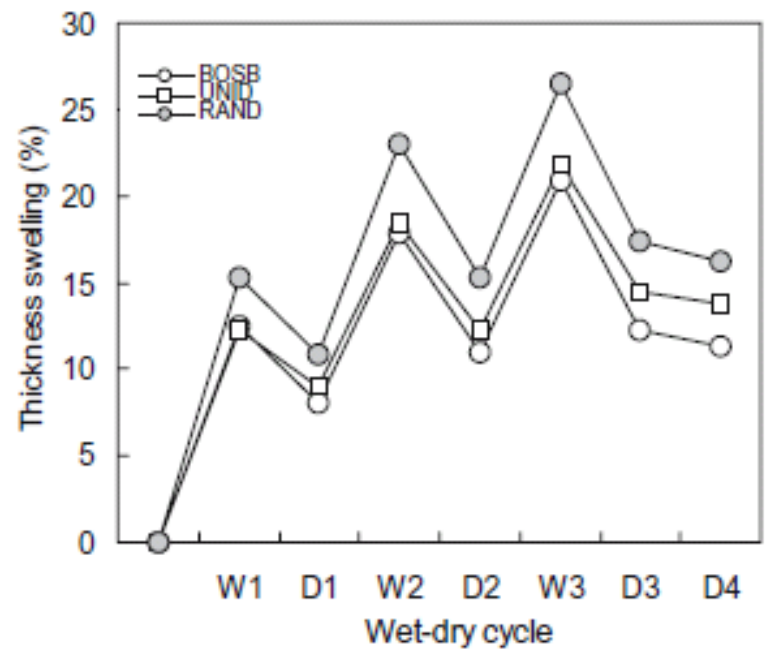

Fig. 6. Effect of layer structure on thickness swelling (TS) tested under a cyclic wet-dry aging treatment with $0.65 \mathrm{~g} / \mathrm{cm}^{3}$ board density. First cycle: specimens were soaked in $20^{\circ} \mathrm{C}$ water for $24 \mathrm{~h}(W 1)$ and then dried at $50^{\circ} \mathrm{C}$ for $22 \mathrm{~h}(D 1)$; second cycle: specimens were soaked in $70^{\circ} \mathrm{C}$ water for $2 \mathrm{~h}(\mathrm{~W} 2)$ and dried at $50^{\circ} \mathrm{C}$ for 22 $\mathrm{h}(D 2)$; third cycle: specimens were soaked in $100^{\circ} \mathrm{C}$ water for $2 \mathrm{~h}(W 3)$ and dried at $50^{\circ} \mathrm{C}$ for $22 \mathrm{~h}(D 3)$. After these treatments, specimens were conditioned at $25^{\circ} \mathrm{C}$ and $65 \pm 5 \%$ relative humidity until equilibrium was reached (D4)

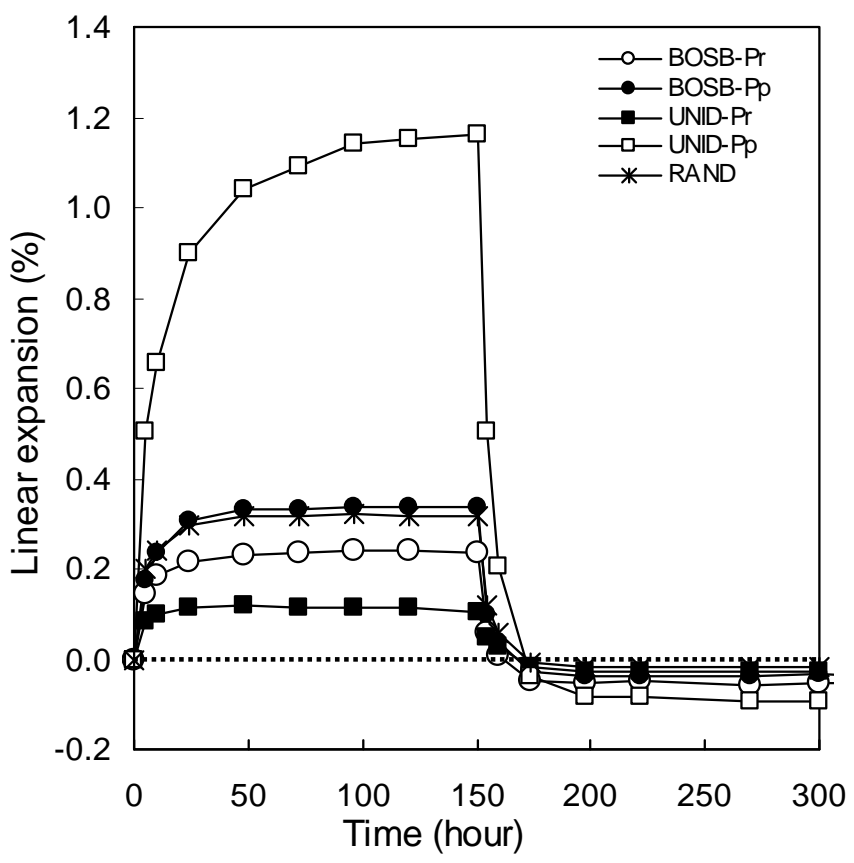

Fig. 7. Effect of layer structure on linear expansion (LE) with $0.65 \mathrm{~g} / \mathrm{cm}^{3}$ board density under humid conditions followed by dry conditions 